\#USGS science for a changing world
Prepared in Coordination with the Federal Emergency Management Agency, National Science Foundation, and National Institute of Standards and Technology

\section{The Plan to Coordinate NEHRP Post-Earthquake Investigations}
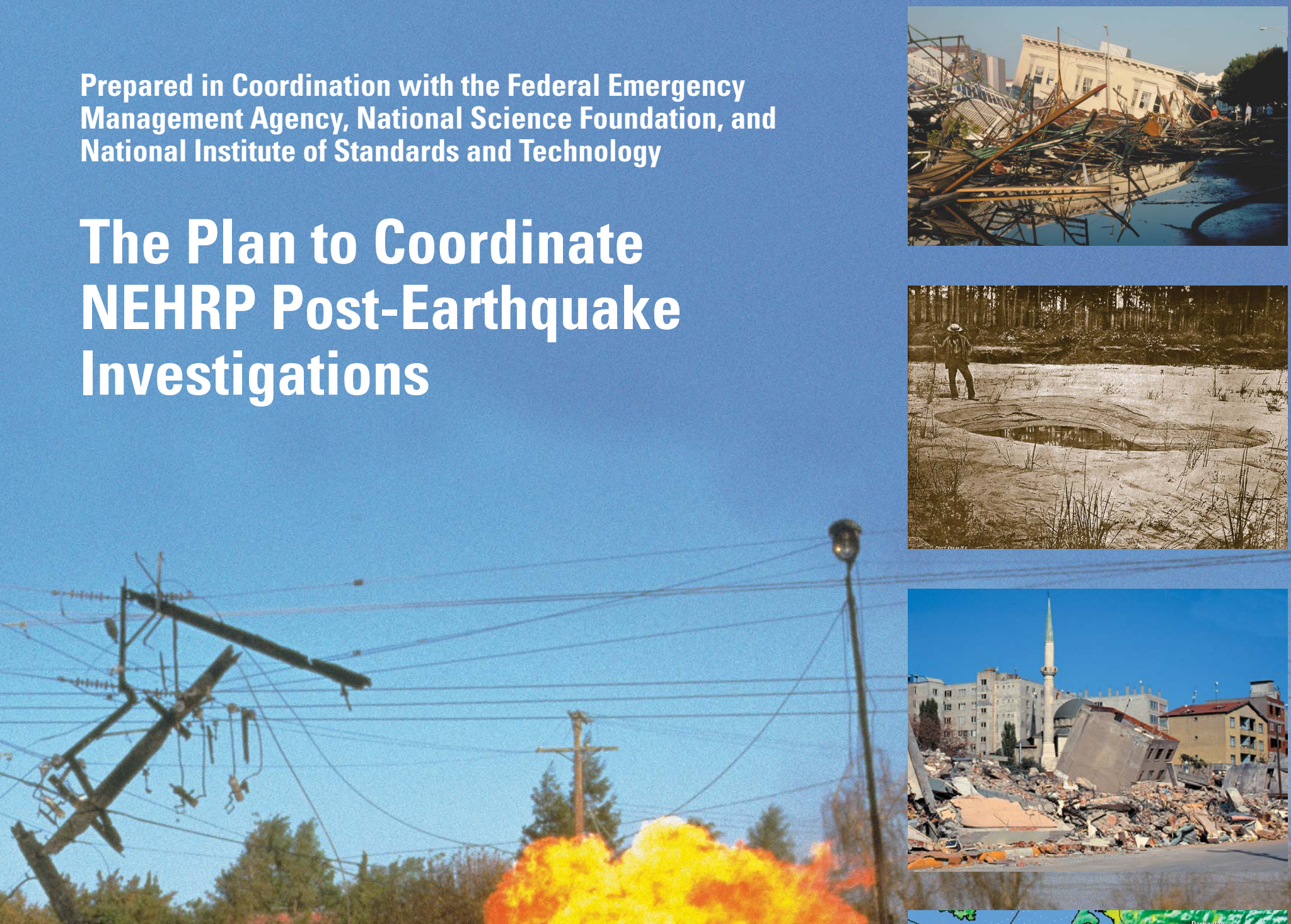

nat

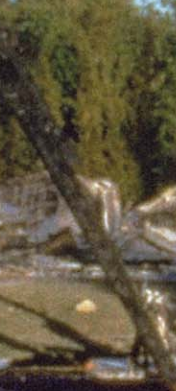

Circular 1242 I. fort

$\frac{83}{3}$

U.S. Department of the Interior

U.S. Geological Survey
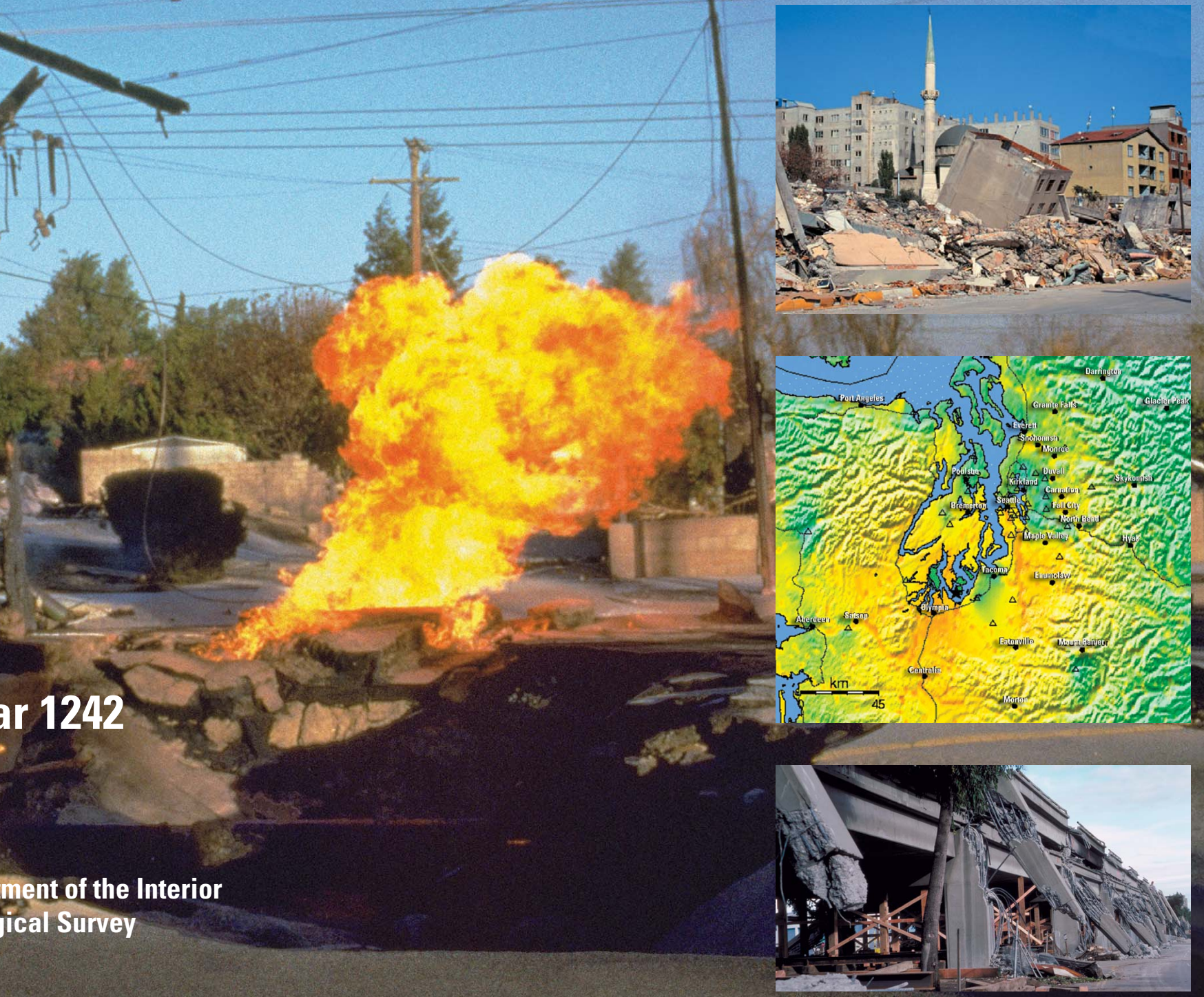
This plan was developed with the assistance of the Applied Technology Council (ATC) of Redwood City, California, under USGS cooperative agreement 1434-WR97-AG-00015, ATC-35. Input for the plan was solicited at a workshop that was co-sponsored by the Earthquake Engineering Research Institute (EERI).

\section{Oversight Committee}

Daniel Abrams, Mid-America Earthquake Engineering Research Center

Jonathan Bray, Pacific Earthquake Engineering Research Center

James Davis, Association of American State Geologists

Richard Eisner, California Office of Emergency Services

William Elliott, American Society of Civil Engineers, Technical Council on Lifeline Earthquake Engineering

Richard Fragaszy, National Science Foundation, Division of Civil and Mechanical Systems, Arlington

Edward Fratto, Northeast States Emergency Consortium

Robert Hendershot, Structural Engineers Association of California

Leigh House, National Science Foundation, Division of Earth Sciences

Thomas Jordan, Southern California Earthquake Center

George Lee, Multidisciplinary Center for Earthquake Engineering Research

Jill McCarthy, U.S. Geological Survey

Rawn Nelson, National Council of Structural Engineers Associations

Timothy Sheckler, Federal Emergency Management Agency

S. Shyam Sunder, National Institute of Standards and Technology

Susan K. Tubbesing, Earthquake Engineering Research Institute

Frank Vernon, Incorporated Research Institutions for Seismology

James Wilkinson, Jr., Central United States Earthquake Consortium

Phillip Yen, Federal Highway Administration 


\section{The Plan to Coordinate NEHRP Post-Earthquake Investigations}

By

Thomas L. Holzer, U.S. Geological Survey, Chairperson

Roger D. Borcherdt, U.S. Geological Survey

Craig D. Comartin, Comartin-Reis

Robert D. Hanson, University of Michigan

Charles R. Scawthorn, ABS Consulting (formerly EOE International)

Kathleen Tierney, University of Delaware

T. Leslie Youd, Brigham Young University

Prepared in Coordination with the Federal Emergency Management Agency,

National Science Foundation, and National Institute of Standards and Technology

\section{Circular 1242}

U.S. Department of the Interior

U.S. Geological Survey 


\section{U.S. Department of the Interior \\ Gale A. Norton, Secretary}

\section{U.S. Geological Survey \\ Charles G. Groat, Director}

U.S. Geological Survey, Reston, Virginia: 2003

For additional copies please contact:

USGS Information Services

Box 25286

Denver, CO 80225

This report and any updates to it are available at http://geopubs.wr.usgs.gov/circular/c1242/

Additional USGS publications can be found at http://geology.usgs.gov/products.html

For more information about the USGS and its products:

Telephone: 1-888-ASK-USGS (1-888-275-8747)

World Wide Web: http://www.usgs.gov/

Any use of trade, product, or firm names in this publication is for descriptive purposes only and does not imply endorsement by the U.S. Government.

Published in the Western Region, Menlo Park, California

Manuscript approved for publication, August 28, 2002

Text edited by James W. Hendley II

Production and design by Susan Mayfield 


\section{Contents}

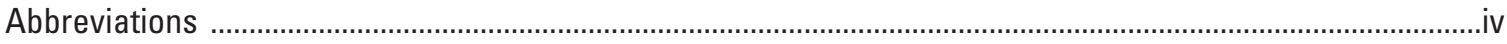

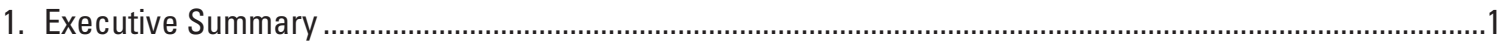

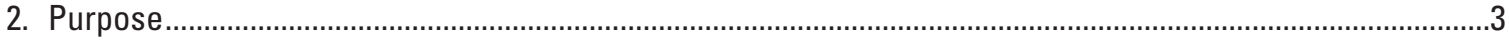

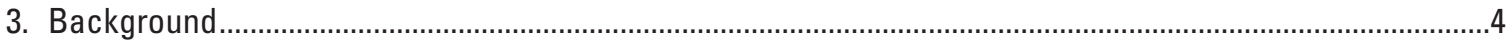

4. NEHRP Post-Earthquake Coordination Plan............................................................................................

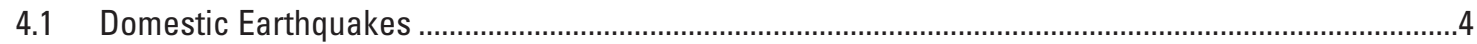

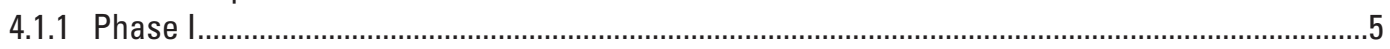

4.1.1.1 Incident Report and Plan Implementation (USGS) ..................................................

4.1.1.2 Web Site Management (USGS) ..............................................................................

4.1.1.3 Technical Clearinghouse (USGS, FEMA, EERI) ..........................................................

4.1.1.4 NEHRP Investigations Coordinator (USGS) ……..........................................................

4.1.1.5 National Construction Safety Team Act (NIST) …………….......................................

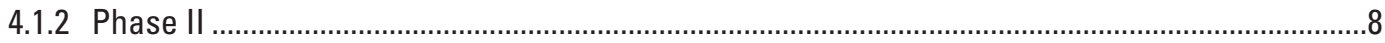

4.1.2.1 Phase II Meeting (Investigations Coordinator) ...............................................................

4.1.2.2 Budget Supplemental Decision (FEMA, NIST, NSF, USGS) ...........................................

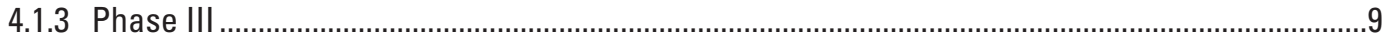

4.1.3.1 Workshop for Setting Investigation Priorities (NSF, USGS, FEMA, NIST) ...................9

4.1.3.2 Information Dissemination (USGS, NSF, FEMA, NIST) ............................................10

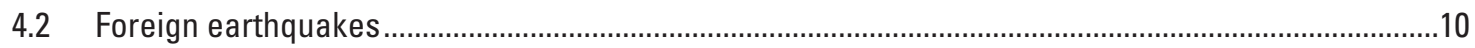

5. Recommendations for Further Action ............................................................................................................12

5.1 Recommendation 1—Broaden Coverage and Comprehensiveness of Investigations of

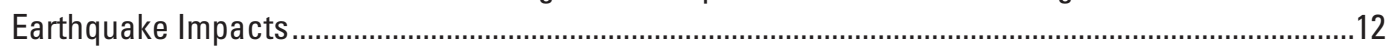

5.2 Recommendation 2-Encourage Use of Information Technology ...................................................14

5.3 Recommendation 3 -Formalize Data Management and Archiving ..................................................15

5.4 Recommendation 4-Funding to Support Post-Earthquake Investigations...........................................15

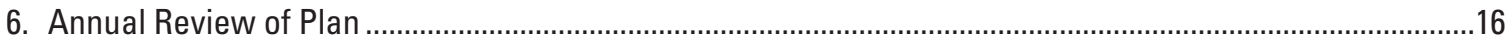

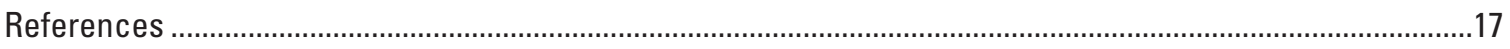

\section{Figures}

1. Activities timeline for NEHRP Post-Earthquake Coordination Plan—Domestic earthquakes .......................5

2. Investigators meet at technical clearinghouse to discuss findings from field investigation of 2001

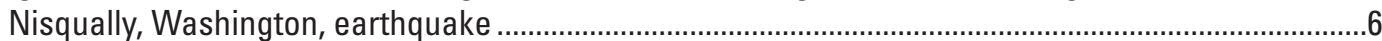

3. Activities timeline for EERI post-earthquake activities —Foreign earthquakes ..............................................11 


\section{Abbreviations}

ANSS, Advanced National Seismic System

ASCE, American Society of Civil Engineers

ATC, Applied Technology Council

COSMOS, Consortium of Strong-Motion Observation Systems

CERI, Center for Earthquake Research and Information

CUSEC, Central United States Earthquake Consortium

CUREE, Consortium of Universities for Research in Earthquake Engineering

DFO, Disaster Field Office

DLESE, Digital Library for Earth Science Education (NSF)

EERI, Earthquake Engineering Research Institute

FCO, Federal Coordinating Official

FEMA, Federal Emergency Management Agency

GIS, Geographic Information System

GPS, Global Positioning System

HAZUS৫, Hazards United States

ICC, NEHRP Interagency Coordinating Committee

InSAR, Interferometric Synthetic Aperture Radar

IRIS, Incorporated Research Institutions for Seismology

IT, Information technology

LIDAR, Light detection and ranging

MAE, Mid-America Earthquake Center

MCEER, Multidisciplinary Center for Earthquake Engineering Research

NAVSTAR, The U.S. constellation of GPS satellites

NAWAS, National Warning System

NCEA, National Council of Structural Engineers Associations

NCST, National Construction Safety Team

NEED, National Earthquake Experience Database

NEES, Network for Earthquake Engineering Simulation

NEHRP, National Earthquake Hazards Reduction Program

NEIC, National Earthquake Information Center

NIST, National Institute of Standards and Technology

NISEE, National Information Service for Earthquake Engineering

NSF, National Science Foundation

PDA, Personal Digital Assistant

PEER, Pacific Earthquake Engineering Research Center

SCADA, Supervisory Control and Data Acquisition System

SCEC, Southern California Earthquake Center

SCO, State Coordinating Official

SGER, Small (NSF) grants for exploratory research

SSA, Seismological Society of America

TCLEE, Technical Council on Lifeline Earthquake Engineering

UNAVCO, University NAVSTAR Consortium

USGS, United States Geological Survey

WSSPC, Western States Seismic Policy Council 


\section{The Plan to Coordinate NEHRP Post-Earthquake Investigations}

\section{Executive Summary}

This is the plan to coordinate domestic and foreign post-earthquake investigations supported by the National Earthquake Hazards Reduction Program (NEHRP). The plan addresses coordination of both the NEHRP agencies-Federal Emergency Management Agency (FEMA), National Institute of Standards and Technology (NIST), National Science Foundation (NSF), and U. S. Geological Survey (USGS) - and their partners. The plan is a framework for both coordinating what is going to be done and identifying responsibilities for post-earthquake investigations. It does not specify what will be done. Coordination is addressed in various time frames ranging from hours to years after an earthquake. The plan includes measures for (1) gaining rapid and general agreement on high-priority research opportunities, and (2) conducting the data gathering and field studies in a coordinated manner. It deals with identification, collection, processing, documentation, archiving, and dissemination of the results of post-earthquake work in a timely manner and easily accessible format.

For the purposes of this plan a significant domestic earthquake is defined as either (1) an earthquake resulting in a Presidential disaster declaration, or (2) an earthquake considered by NEHRP agencies to provide an opportunity to learn how to reduce future earthquake losses in the United States. The plan organizes domestic post-earthquake investigation and information dissemination activities into three phases, which include the following elements:

\section{Phase I (immediate to several days)}

- Incident Report and Plan Implementation-Within a few minutes after a large or potentially damaging domestic earthquake, the USGS shall notify emergency managers, NEHRP agencies, state geological survey(s) in the affected state(s), and personnel designated by the NEHRP agencies. Following this incident report, the USGS shall convene with FEMA, NIST, NSF, the state geological survey(s), and the Earthquake Engineering Research Institute (EERI) to determine if the earthquake is significant and warrants implementation of either all or part of the NEHRP post-earthquake coordination plan. Immediately following this consultation, the USGS in cooperation with FEMA and the state geological surveys shall alert emergency management agencies about implementation of the plan.
- Web Site Management-Within hours of the event, the USGS shall establish an event Web site with links to other earthquake-related Web sites. The USGS shall have principal responsibility for collating and linking to earthscience information. EERI shall have principal responsibility for collating and linking to engineering information as provided by engineering centers, institutions, and private practice.

- Technical Clearinghouse-Within 24 hours following mutual consultation, the USGS, FEMA, and EERI will work with state agencies to organize a field technical clearinghouse. Depending on ability and capability, the affected state(s) may take the lead in organizing the clearinghouse. California already has formalized the process for establishing a clearinghouse, with the principal NEHRP-sponsored participants being FEMA (Region IX), EERI, and the USGS. State planning currently is being conducted for the central and western United States under the aegis of the Central United States Earthquake Consortium (CUSEC) and the Western States Seismic Policy Council (WSSPC). The clearinghouse is the focal point for coordinating activities and promoting the safety of all field parties during initial post-earthquake reconnaissance.

- NEHRP Investigations Coordinator-Within 24 hours of a significant earthquake, the USGS in consultation with the other NEHRP agencies shall designate a NEHRP Investigations Coordinator. The Coordinator shall be kept abreast of all NEHRP activities and relevant communications with regards to the earthquake, ensure liaison with emergency managers is adequate, and assist the NEHRP agencies to optimize the deployment of NEHRP resources and to establish priorities for investigations.

- NCST Investigation-Within 48 hours, NIST will examine the relevant factors associated with building failures that occur as a result of the earthquake and will make reasonable efforts to consult with the other NEHRP agencies prior to determining whether to conduct an investigation under the National Construction Safety Team (NCST) Act. Any NIST investigation conducted under the authority of the Act will be limited to building failures on one or more buildings or on one or more class or type of buildings selected by NIST.

\section{Phase II (several days to 1 month)}

- Meeting-When the initial reconnaissance phase nears completion, the NEHRP Investigations Coordinator shall 
convene a meeting to identify opportunities and needs for rapid concentrated data gathering and investigation, including systematic collection of perishable data. Within 24 hours of the meeting, the Coordinator shall prepare a report containing summary reconnaissance findings, recommendations for collection of perishable data, and an estimate of both the level of effort and amount of funding that will be required to conduct recommended activities. On the basis of this report and pending available funds, NEHRP agencies may invite, consider, and support proposals for rapid investigations. The Coordinator shall be kept informed of all NEHRP-supported investigations in order to facilitate coordination and minimize duplication of effort.

- Budget Supplemental Decision-If the earthquake presents opportunities for investigations that would improve earthquake risk mitigation, but which cannot be supported with existing funds, the NEHRP agencies shall convene within a few days after the earthquake to consider a request for a budget supplemental.

\section{Phase III (1 month to 5 years)}

- Workshop on Investigation Priorities-Within 1 to 2 months of the earthquake, NSF and the USGS shall jointly sponsor a multidisciplinary workshop to evaluate both short- and long-term research and development opportunities, including what intensive follow-up investigations are warranted. The workshop will identify major opportunities and recommend priorities for funding.

- Investigations Solicitation-Based on the outcomes of the Workshop on Investigation Priorities and within constraints of available funding, a joint statement may be issued by FEMA, NSF, USGS, and NIST that solicits proposals for long-term research and problem-focused studies. If possible, awards are to be made within 5 months of the event.

- Information Dissemination-NEHRP shall support at a minimum three types of information dissemination activities following every significant domestic earthquake.

(1) An event summary report for a broad audience shall be published within 3 months of the event. The report shall integrate preliminary observations on the response of the natural, built, and socioeconomic environments. It shall be prepared by the USGS and EERI in collaboration with other NEHRP supported investigators and institutions.

(2) On the first anniversary of the earthquake, FEMA, NIST, NSF, and the USGS, shall support local and state agencies involved in risk reduction to hold a public conference with an accompanying proceedings that summarizes the implications of the earthquake and identifies opportunities for earthquake risk reduction. The conference and proceedings shall be targeted at local and state decisionmakers and shall be held in the region impacted by the earthquake. Participation by Federal stakeholders shall be encouraged as well.
(3) A comprehensive synthesis of research and professional reports shall be published within 5 years of the event by the USGS and NIST. Data and other detailed information shall be archived in a NEHRP virtual data center and appropriately summarized in the synthesis report. If NIST is conducting an investigation under the authority of the National Construction Safety Team Act, NIST will contribute to the publications described above to the extent possible.

For foreign earthquakes, which typically are less intensively investigated than domestic earthquakes, the plan recommends that all U.S. post-earthquake investigators inform EERI of plans and schedules of investigations before departure, as well as their ongoing status once in the field. EERI shall regularly report these planned activities and their status to the NEHRP agencies as well as on its Web site. NEHRP agencies shall monitor these plans to avoid interference by visiting U.S. investigators with local experts.

This proposed plan concludes with recommendations that address several deficiencies in current domestic post-earthquake investigations. The deficiencies were identified at an invitational workshop of experienced post-earthquake investigators held as part of the process to prepare this plan. Areas in need of major improvement include:

- Coverage and comprehensiveness of investigations of earthquake impacts, including performance of the built and socioeconomic environments.

- Application of new information technology to data collection.

- Data management and archiving.

The plan recommends that NEHRP develop standard formats for the collection of data on the performance of buildings and other structures in regions of severe ground shaking, including damage to nonstructural components and information characterizing the earthquake resisting properties of structures. The standard formats for data collection shall consider those already developed for existing damage prediction tools, such as HAZUS@, as well as current standardized procedures for seismic design, pre-event evaluation and rehabilitation, and post-event evaluation and repair of structures. All post-earthquake data, including that accumulated by both FEMA as part of the disaster assistance process and private structural engineering firms, should be both collected digitally and stored in a virtual Web-based archive. This new database could be maintained either by the Network for Earthquake Engineering Simulation (NEES) or at various sites from where data would be retrievable from a single or mirrored Internet site using time stamps and a georeferencing system. The database would be addressable using all of the tools of a modern geographic information system as well as using modern relational database technology on the Internet. NEHRP also should involve a wider range of disciplines, including economics, sociology, and political science, in post-earthquake investigations. Protocols for data collection in these disciplines also should be standardized. 
Because much of this information helps to reduce future losses, it is important that adequate funding be available for domestic post-earthquake investigations. For example, domestic post-earthquake investigations for each significant earthquake could be funded by establishing a separate fund during the next NEHRP reauthorization that could then be drawn upon for Federally-declared earthquake disasters; such funds could be administered by FEMA. Another possibility could be to designate and utilize existing agency programs to fund these activities. However, in the absence of such funds, all of the NEHRP agencies shall be prepared to submit a request through FEMA to Congress for appropriate emergency supplemental funding following a significant domestic earthquake. Such a template could also be used for post-event investigations of other types of disasters, including natural and terrorist events, which would allow for the documentation of information that would help improve the protection of the Nation's infrastructure from future events.

\section{Purpose}

This report presents the plan to coordinate domestic and foreign post-earthquake investigations supported by the National Earthquake Hazards Reduction Program (NEHRP). As has been demonstrated in numerous disasters, authoritative and timely scientific and engineering advice after a disaster both improves emergency response and helps allay public fears and anxiety. Large urban earthquakes in the United States can cause many fatalities and great property loss. It is likely after a great earthquake that the Nation will turn to officials of NEHRP for authoritative advice following these inevitable events. By coordinating its post-earthquake response, NEHRP will be in a stronger position to provide input and work effectively with officials involved in the post-earthquake emergency response activities.

Major earthquakes also provide critical information on earthquake processes, ground shaking, and the performance of the built and socioeconomic environments. A set of coordinated efforts during and following the event can enhance the information acquired. The nature and quality of this information can significantly reduce losses not only immediately following the specific event, but also from future events through improved planning, design, and construction. The infrequency of large damaging earthquakes and the many NEHRP-supported investigators who can be expected to conduct field studies after earthquakes require that post-event investigations be closely coordinated in order to maximize the learning that will improve mitigation of the effects of future earthquakes. Postearthquake investigations are critical for:

- Providing insight into why and how faults rupture.

- Understanding and predicting shaking and secondary ground deformation.

- Documenting and improving performance of the built environment.

- Evaluating the adequacy of current building standards and practices.
- Documenting societal and economic impacts and providing information for improving earthquake response and recovery activities.

- Identifying specific opportunities to mitigate the impacts of future earthquakes.

In summary, benefits from post-earthquake investigations can include improved emergency response, a safer built environment, cost-effective construction of new structures and rehabilitation of older ones, improved land-use practices, and better understanding of earthquake hazards in the United States.

This plan provides a framework for both coordinating what is going to be done and identifying responsibility for post-earthquake activities. It does not and cannot specify what will be done because each earthquake offers different challenges and learning opportunities. The plan applies primarily to the NEHRP Federal agencies and their partners, which range from state agencies, multi-state consortia, the Earthquake Engineering Research Institute (EERI), the NSF-funded centers and organizations for earth science and earthquake engineering research and education, the Network for Earthquake Engineering Simulation (NEES), to other academic and professional groups with professional interests in post-earthquake investigations. It is important to recognize that NEHRP post-earthquake activities primarily consist of information gathering and documentation of what happened. Some of this information, however, is of immediate interest to emergency managers and the public. NEHRP agencies and partners need to convey this information in a timely manner. The primary responsibility is to alert the public and Federal and state agencies about the occurrence and scope of the event. However, NEHRP investigators must be prepared to convey other aspects that bear on public safety or concerns.

In addition to proposing a structure to improve coordination of the activities and investigations that typically are conducted following significant earthquakes, the plan also identifies new activities - some of which are permitted by advances in technology - that are considered significant to improve loss reduction in future earthquakes. These activities and a mechanism for their funding are described in four recommendations. Their implementation would substantially improve the contribution of NEHRP post-earthquake investigations to earthquake risk reduction in the United States.

Earthquakes are one of several hazards that can cause large disasters that result in great loss of life and property. The most significant of these are hurricanes, floods, winter storms, tornadoes, wildfires, volcanic eruptions, landslides, and terrorism. Indeed, from 1992 to 1996, losses in the U.S. from natural hazards averaged about \$1 billion per week (OSTP, 1997). Post-event documentation of these hazards and their consequences contributes significantly to improvements in mitigating their impact and thereby reduces future losses. Although scientific and technical aspects of these hazards may differ, post-disaster investigations pose many similar challenges. Thus, this plan for post-earthquake coordination should be useful for planning and coordinating investigations of these other hazards. 


\section{Background}

The 2001-2005 NEHRP Strategic Plan (FEMA, in press) stresses the importance of post-earthquake investigations. NEHRP has long supported post-earthquake investigations including efforts in the earth sciences, engineering, and socioeconomic disciplines. Improved coordination is necessary if these investigations are to maximize learning through the sharing of information. Because the USGS has the statutory responsibility and authority under Public Law 101-614 to conduct post-earthquake investigations, the Strategic Plan tasks NEHRP under the leadership of the USGS to (1) examine the roles and responsibilities of the various groups involved in post-earthquake investigations and (2) develop a NEHRP protocol action plan as well as a funding mechanism for investigations following major domestic and foreign earthquakes. According to the Strategic Plan, the NEHRP protocol action plan should detail the degree of coordinated learning desired, how those findings will be obtained, and how findings can be most effectively disseminated to all stakeholders in a comprehensive, multidisciplinary NEHRP report. The objectives of the present plan are to improve coordination during post-earthquake investigation efforts, minimize duplication of efforts, identify activities that could be supported with additional resources (such as disaster funds from FEMA or supplemental appropriations), and maximize the opportunity to learn from both domestic and foreign earthquakes.

To develop the NEHRP protocol action plan, the USGS requested the assistance of the Applied Technology Council (ATC) of Redwood City, California, under USGS cooperative agreement 1434-WR-97-AG-00015, ATC-35. ATC organized a multidisciplinary 7-member committee to draft the plan and a multi-institutional oversight committee to review the plan. Input was solicited from experienced post-earthquake investigators and NEHRP agencies at an invitational workshop held March 13-14, 2001, in Menlo Park, California. The workshop was jointly sponsored with EERI. Based on input from the workshop, a draft plan was prepared. In addition to the review by the oversight committee, comments were solicited from the general post-earthquake investigation community on a draft posted on the ATC Web site. The present plan is the result of this manifold input and comment process.

\section{NEHRP Post-Earthquake Coordination Plan}

The plan addresses coordination during three time frames or phases after the earthquake:

- Phase I-Post-earthquake reconnaissance during the first few days.

- Phase II-Intensive gathering and archiving of perishable data during the first few weeks.

- Phase III-Research and investigations, including additional data gathering and archiving, conducted during the subsequent months and years.

The response of NEHRP to domestic and foreign earthquakes is sufficiently different in scope that earthquakes occurring in the United States and abroad are treated separately. Domestic earthquakes provide NEHRP with its best opportunity to evaluate seismic hazards and the performance of the built and socioeconomic environments in the United States. Furthermore, NEHRP is directed to conduct investigations of domestic events by the 1977 Earthquake Hazards Reduction Act. Consequently, domestic earthquakes typically receive greater scrutiny by NEHRP than do foreign earthquakes. Foreign earthquakes, however, usually provide insight into crustal failure processes, seismic radiation fields, and some construction practices that contribute to earthquake risk mitigation in the United States, as well as opportunities for model validation. For example, about $\$ 1.5$ million in NEHRP funds was used to support U.S. research investigations of the 1999 Kocaeli, Turkey, and Chi-Chi, Taiwan, earthquakes. In some cases, such as the 1988 Spitak, Armenia, and the 1999 Kocaeli, Turkey, earthquakes, the affected countries request specific technical assistance from the U.S. Government, and these requests are usually fulfilled by NEHRP agencies.

\subsection{Domestic Earthquakes}

The proposed plan to coordinate post-earthquake investigations for significant domestic earthquakes is shown schematically in figure 1. For the purpose of implementing the plan, either in part or in total, a significant domestic earthquake will be defined as follows: (1) an earthquake resulting in a Presidential disaster declaration or (2) an earthquake considered by NEHRP agencies to provide an opportunity to learn how to reduce future earthquake losses in the United States. The plan identifies the steps and approximate timeline necessary to achieve coordination goals, as well as the parties responsible for each activity. The responsible parties include NEHRP agencies, entities funded either in part or totally by NEHRP, and other entities with whom NEHRP should coordinate. As shown in the figure, these activities are parts of a continuum. Initial or Phase I post-earthquake activities focus on defining the scope of the disaster and are reconnaissance in nature. They quickly assess the character and distribution of inflicted damage and generated ground effects, identify research opportunities that will improve the practice of earthquake risk mitigation, set the stage for subsequent in-depth data gathering, and aid emergency managers by identifying hazardous situations that may be exacerbated by aftershocks or other processes. These Phase I activities are typically followed by more intensive data gathering for subsequent research and analysis. This period is commonly referred to as Phase II and may last for weeks after the event. Phase III is the longer period after the earthquake when comprehensive research and investigations are conducted.

Most of the activities identified in the plan are currently conducted by NEHRP following domestic earthquakes. The plan is designed to place them into a more formal structure. Some of the activities, particularly those that apply new information technology, are evolving with each earthquake. For these activities, the plan tries to anticipate their evolution and assign responsibility for their implementation. 


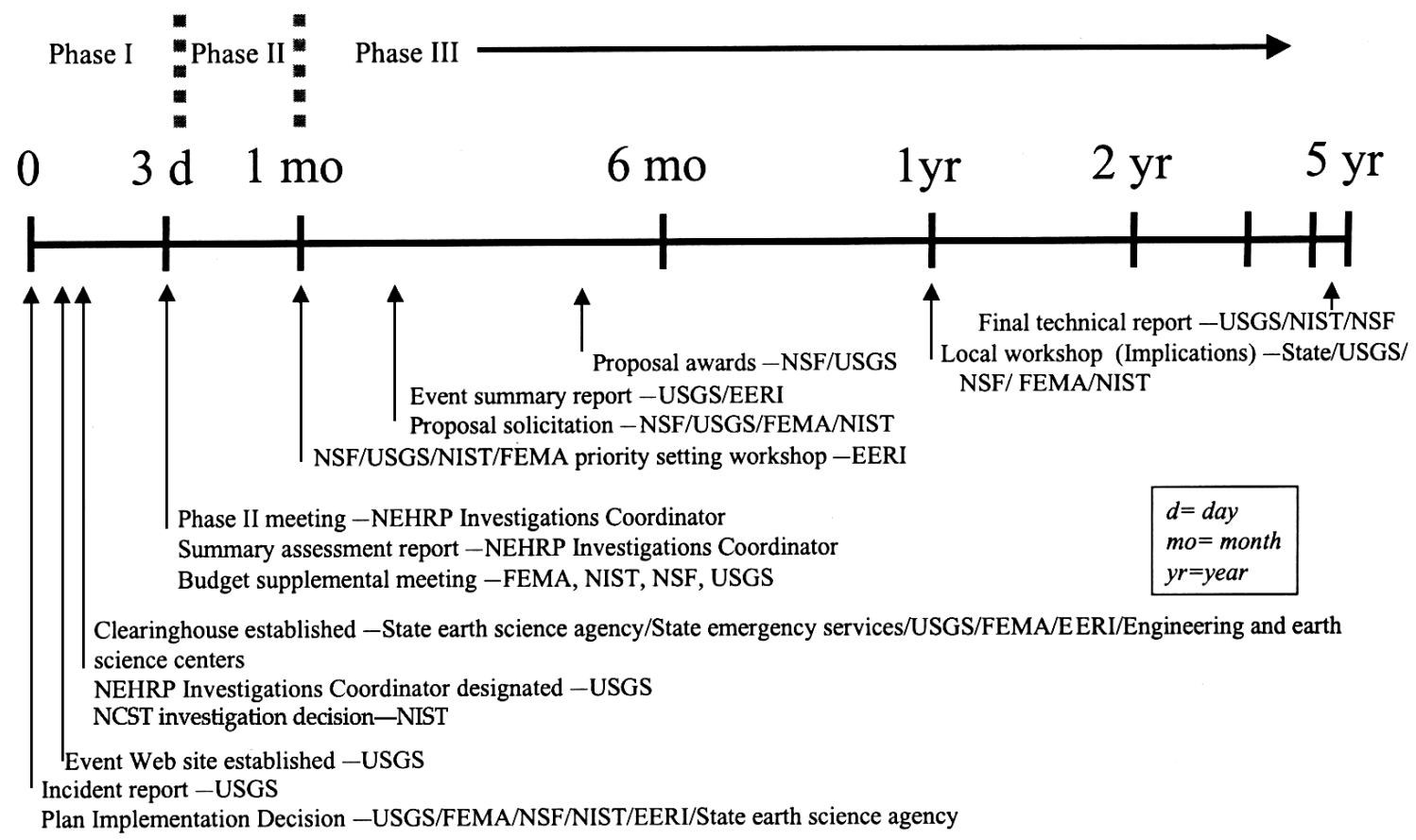

Figure 1. Activities timeline for NEHRP Post-Earthquake Coordination Plan-Domestic earthquakes.

\subsubsection{Phase I}

Following the USGS incident report and decision by the NEHRP agencies to activate the plan, several decisions must be made promptly by NEHRP. These decisions occur almost simultaneously. They include: (1) activation of an event web site, (2) establishment of a field technical clearinghouse, and (3) designation of an Investigations Coordinator.

\subsubsection{Incident Report and Plan Implementation (USGS)}

When a large or potentially damaging earthquake occurs in the United States, the USGS shall determine and announce the magnitude and location of the earthquake within minutes. Once announced, emergency response personnel are alerted through the National Warning System (NAWAS), which is operated by FEMA. As development of the Advanced National Seismic System (ANSS) progresses, the USGS capability to estimate the strength and geographic distribution of strong shaking will also improve. The USGS has the mandate to quickly provide information on the strength and distribution of strong ground shaking to emergency managers and others. The improved ANSS system is greatly improving the capability of USGS to fulfill this mandate.

Each NEHRP agency shall identify (and review annually) a contact who shall be alerted directly by the USGS about the event. Each NEHRP agency also should develop a list and strategy for contacting entities that have partnership responsibilities in the area of post-earthquake investigation. Examples of such entities include EERI, state geological surveys and regional associations, earth science centers, and NSF-funded centers for earthquake engineering research and education.
These entities should request that the USGS provide automatic e-mail alerts, which can be received on cell phones, pagers, and computers.

Following the incident report, the USGS shall convene a conference call with the NEHRP agencies, the state geological survey(s) in the affected state(s), and EERI to determine if the earthquake is significant. If the earthquake is deemed significant, the USGS in consultation with the preceding agencies and organizations shall decide whether to implement all or part of the NEHRP post-earthquake coordination plan. If the decision is made to implement the plan, the USGS in collaboration with the state geological surveys shall inform emergency management agencies of the implementation.

\subsubsection{Web Site Management (USGS)}

Under the plan, the USGS shall be responsible for establishing, within a few hours of a significant earthquake, an event Web site with links to other Federal and non-Federal earthquake-related Web sites. The USGS has recently automated this process for any domestic earthquake with a magnitude of 6.5 or greater and foreign earthquakes with a magnitude of 7.0 or greater; smaller events may still be significant, however, and regional earthquake information centers will need to adopt and modify the automatic posting criteria to best meet the needs of their region. Beginning with the devastating earthquake in 1995 in Kobe, Japan, the Internet has become an important source of information about earthquake disasters for both technical personnel and the public.

To facilitate searches for the event Web site, its URL and a link shall be posted on the USGS Earthquake Program Web site (http://earthquake.usgs.gov) and the EERI Web site (http: 
//www.eeri.org). The event Web site shall include brief descriptions of linked sites so that earth scientists, engineers, and social scientists will be able to search efficiently for information about the earthquake. Entities that are funded by NEHRP agencies and that establish Web sites shall be instructed by their funding agencies to inform the USGS of their URL and provide the USGS with a brief description or abstract of the Web site. The USGS event Web site also shall include information about the location of and activities at the technical clearinghouse (see 4.1.1.3). The Web site shall include authoritative sources of information; the USGS, EERI, and FEMA have responsibility, respectively, for earth science, engineering, and Federal disaster information and assistance. The USGS shall have principal responsibility for collating and linking to earth-science information. EERI shall have principal responsibility for collating and linking to engineering information as provided by the engineering centers, institutions, and private practice.

The USGS Earthquake Hazards Program along with the USGS regional and National Earthquake Information Center (NEIC) Web sites will be critically important sources of basic information for the news media and general public in the first few hours following a damaging earthquake. Commonly the demand for information surges several orders of magnitude during this period. In the past, the USGS has had difficulty in meeting this surge in demand; accordingly the USGS has recently contracted with a private vendor for web content distribution. It is important that the USGS continue to employ a web-content distribution strategy that is scaleable and designed to perform well during peak periods. This will ensure that the media, the general public, and responding officials, all have information about what is happening as soon as it is available.

\subsubsection{Technical Clearinghouse (USGS, FEMA, EERI)}

Within 1 day after a significant earthquake, a place should be established in the region affected by the earthquake where post-earthquake field investigators can meet to review progress and to organize and coordinate their activities. For very large events, multiple places might be appropriate. Such a field facility, known as a technical clearinghouse, is increasingly becoming part of the post-earthquake investigation culture in the United States (fig. 2). For purposes of coordination and safety, it is strongly recommended that all field investigators, regardless of affiliation, go through the clearinghouse before conducting field investigations. Formal clearinghouses were established after the 1994 Northridge, California, and 2001 Nisqually, Washington, earthquakes. Establishment of the technical clearinghouse is paramount to ensure an orderly post-earthquake technical reconnaissance that does not interfere with emergency response activities. To meet this goal, direct communication between the clearinghouse and state and Federal Disaster Coordinating Officers needs to be established and maintained. California has formalized the process for establishing a clearinghouse, with the principal NEHRP-sponsored participants being FEMA (Region IX), EERI, and the USGS (OES, 1998). Recently, the Western States Seismic Policy Council (WSSPC) and Central United States Earthquake Consortium (CUSEC) have sponsored efforts to formalize the clearinghouse process

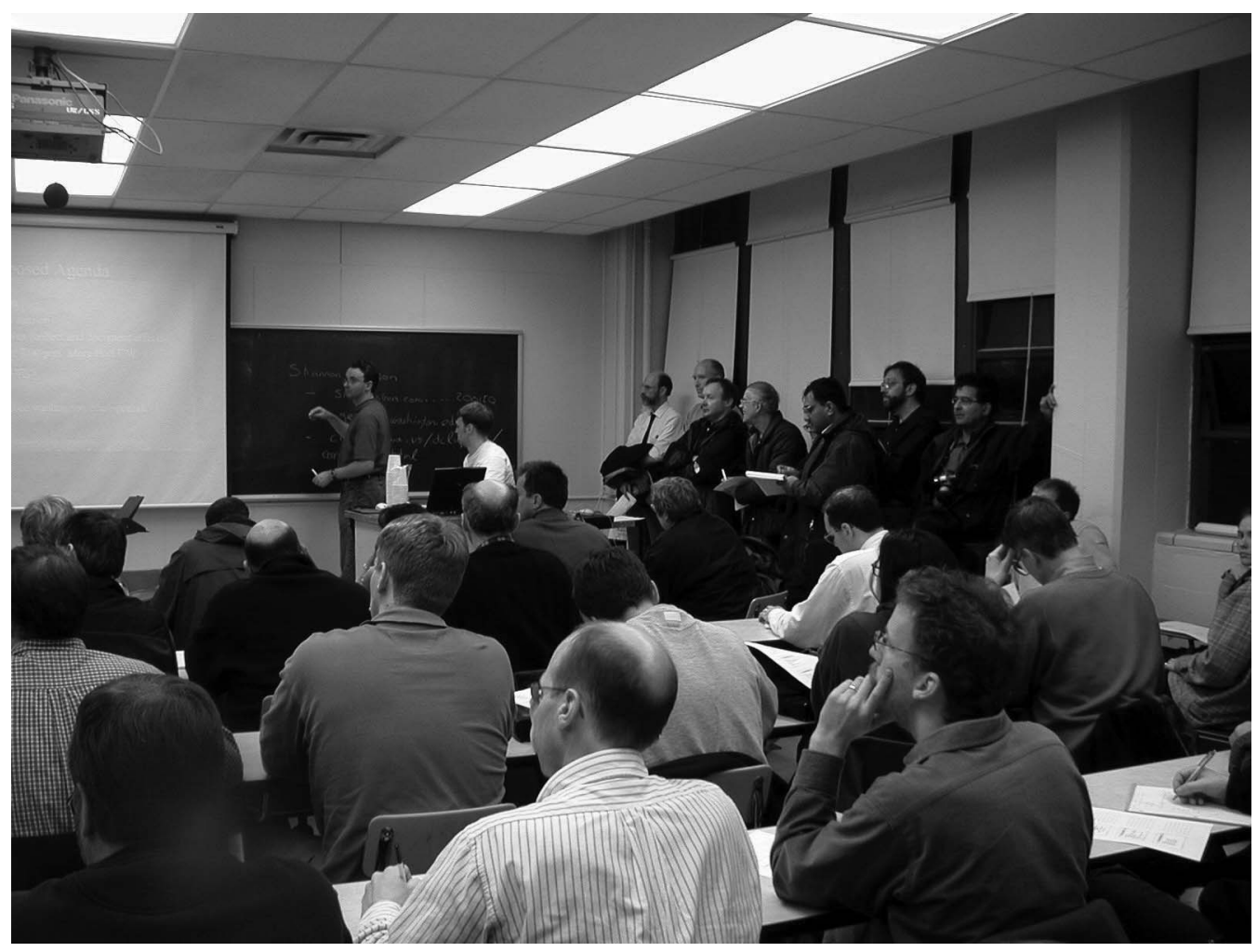

Figure 2. Investigators meet at technical clearinghouse to discuss findings from field investigation of 2001 Nisqually, Washington, earthquake (photograph by Charles Scawthorn). 
in their regions. WSSPC recently both adopted a policy that "each state, province, and territory establish a plan for postearthquake clearinghouses to be activated within 24 hours after each major earthquake..." (WSSPC, 2001) and published a model plan (http://www.wsspc.org/publicpolicy/committees/ clearinghouseplan.pdf). CUSEC, which coordinates earthquakerelated efforts of geological surveys in the central United States, is developing a regional plan that will identify a single point of contact following an event.

The USGS, FEMA, and EERI shall work together on behalf of NEHRP and develop a general procedure for establishing a clearinghouse within 24 hours following a significant earthquake. The procedure shall be formulated in collaboration with state emergency management, state geological surveys, and appropriate multi-state consortia. The degree of leadership or responsibility by NEHRP entities for a specific event will depend on the level of involvement of non-Federal agencies in the clearinghouse. In cases where the states have a clearinghouse plan and resources, a state may take the lead in establishing the clearinghouse, with NEHRP and its affiliated agencies being partners in that effort. In other cases where states are not prepared to establish a clearinghouse, NEHRP shall take the lead in establishing the clearinghouse, with participation as available from state and local agencies. If NIST is conducting an investigation under the authority of the National Construction Safety Team Act, NIST will coordinate with the clearinghouse to the extent possible.

Both the specific design and operation of the clearinghouse are the responsibility of the participants, but general operational plans must be prepared in advance by the USGS, FEMA, and EERI, if a fully functional clearinghouse is to be quickly established. With regards to NEHRP-supported investigations, EERI shall take responsibility for the engineering and socioeconomic aspects of the operation, and the USGS shall take responsibility for the earth science aspects. It is crucial that NEHRP funding agencies encourage funded centers, groups, and individuals to coordinate their activities with either EERI or the USGS through the clearinghouse. It is especially important that academic investigators, students, and technical representatives of the earthquake engineering research and education centers [Mid-America Earthquake Center (MAE), Multidisciplinary Center for Earthquake Engineering Research (MCEER), and Pacific Earthquake Engineering Research Center (PEER)] and earthquake earth science centers and organizations [Southern California Earthquake Center (SCEC), Center for Earthquake Research and Information (CERI), the Incorporated Research Institutions for Seismology (IRIS), and the University NAVSTAR Consortium (UNAVCO)] contribute and participate in the coordination efforts. These centers and organizations comprise a valuable assembly of multidisciplinary expertise in earthquake investigations. In addition, students from these centers can gain first-hand experience and provide valuable support to the technical clearinghouse. USGS shall formalize agreements with the major NEHRP-affiliated earth science centers and organizations to facilitate coordination; EERI shall formalize agreements with the major NEHRP-affiliated engineering centers and professional groups, such as the Technical Council on Lifeline Earthquake Engineering (TCLEE), that routinely investigate earthquakes. It is critically important that these centers and organizations develop plans for post-earthquake investigations and share them with EERI and the USGS. Finally, at the time of an event, participation of faculty and students from universities and colleges, who are not affiliated with either earthquake engineering or earth science centers and organizations, will be welcomed.

Both the operational relation and physical proximity of the technical clearinghouse to the Disaster Field Office (DFO) need to be considered when the clearinghouse is established. Some information collected during the Phase I activity may be relevant to decisions being made at the DFO. Coordination of the clearinghouse with the DFO may also provide a basis for a state's request that the clearinghouse be given a mission assignment by the appropriate state emergency services agency and thereby qualify the clearinghouse for partial funding support from disaster relief funds authorized by the 1974 Robert T. Stafford Disaster Relief and Emergency Assistance Act, as amended (42 U.S.C. 5121, et seq.).

If the earthquake is substantial and receives prominent coverage by the news media, many foreign researchers can be anticipated to visit. The USGS, EERI, and state agencies shall arrange at the clearinghouse to welcome, orient, and possibly brief these visitors about potential sites for their inspection and study as well as safety concerns. Close coordination between U.S. and foreign efforts can augment U.S. expertise and provide assistance with NEHRP post-earthquake investigations. Information directing visiting scientists and engineers to the clearinghouse should be posted on the event Web site.

\subsubsection{NEHRP Investigations Coordinator (USGS)}

Within 1 day of a significant earthquake, a NEHRP Investigations Coordinator shall be designated by the USGS. The USGS shall maintain a list of suitable candidates, both in and out of the Federal service, and ensure that a mechanism is available to retain the full-time services of each individual on short notice for a minimum of 1 month. Preparation of the list and selection of the Coordinator shall be done in consultation with FEMA, NSF, and NIST. The Coordinator shall be an individual with broad technical background, previous post-earthquake investigation experience, and a thorough awareness of the capabilities of the various NEHRP agencies and their affiliated centers and organizations. The primary responsibilities of the Coordinator are (1) to ensure that disaster response activities are not impeded by scientific and technical investigations, (2) to provide emergency managers with timely and relevant information from the ongoing field investigations, (3) to facilitate coordination of NEHRP agencies, (4) to ensure that NEHRP press releases are coordinated and consistent, and (5) to work with scientific and engineering leaders to identify critical investigations and gaps in the ongoing investigation. Because it is impossible to delegate authority to the Investigations Coordinator under NEHRP, program managers in each NEHRP agency must work closely and cooperatively with the Coordinator to take advantage of the broad perspective of the Coordinator. 
The advent of the Internet has greatly facilitated timely communication and reporting during natural disasters. Most organizations involved in post-earthquake investigations routinely provide daily situation reports on findings, progress, and difficulties encountered. Most of these reports are issued as e-mail. The Coordinator shall be (1) informed by each NEHRP agency about the scope of their post-earthquake investigation and (2) copied on all e-mail reports from supervisory field personnel and planning staff when possible. The Investigations Coordinator must also be kept abreast of activities at the technical clearinghouse.

In summary responsibilities of the Investigations Coordinator are to:

- Ensure that liaison with the Federal and State Coordinating Officials (FCO and SCO) and state and local emergency managers is established promptly. The purposes of the liaison activity are to ensure that NEHRP field efforts do not impede emergency response and recovery management and that relevant scientific and technical assessments from the field investigators are appropriately communicated to emergency managers. In addition to the scientific and technical assessments, some physical resources may be useful for emergency response. For example, it may be of value to make emergency managers aware of the Lawrence Livermore National Laboratory portable real-time aftershock warning system that can be shipped on short notice to an impacted area $^{1}$. If a state has already established a liaison person for scientific and technical investigations, the Coordinator should work with the designated state liaison person.

- Identify duplication and gaps in initial field reconnaissance and work with NEHRP program managers and state agencies to improve coordination and rectify shortcomings.

- Work with NEHRP and state agencies and Federal, state, and local emergency managers to ensure that news releases are consistent and helpful to the public.

- Convene and report results from Phase II meeting (see 4.1.2.1).

\subsubsection{National Construction Safety Team Act (NIST)}

Prompted by the collapse of the World Trade Center Towers on September 11, 2001, Congress passed the National Construction Safety Team Act, which was signed into law on October 1, 2002. The Act authorizes the Director of NIST to establish and deploy a Team to investigate the failure of a building or buildings that has resulted in substantial loss of life or that posed significant potential for substantial loss of life. To the maximum extent practicable, the Director shall establish and deploy a Team within 48 hours after such an event.

\footnotetext{
'The aftershock warning system consists of a base station and 8 remote stations. A self-contained broadcasting system sends signals to pagers within 60 miles of the base station. The pagers provide as much as a few seconds warning of potentially hazardous shear-wave arrivals from aftershocks. The pager signals can be used as switches for either automatic response or to emit noise and flashing light.
}

Congress anticipated the Act to be applicable to building failures caused by earthquakes. In section $2(\mathrm{c})(1)(\mathrm{J})$ of the Act, it specifies that the NIST Director develop implementing procedures that "provide for coordination with Federal, State, and local entities that may sponsor research on investigations of building failures, including research conducted under the Earthquake Hazards Reduction Act of 1977." In addition, Committee Report 107-530, published by the House Science Committee on June 25, 2002, states that "The Director should clearly define how earthquake researchers and Teams will carry out their responsibilities in a coordinated fashion in cases where building failures have been caused by an earthquake."

The purpose of the Act is to (1) establish the likely technical cause or causes of the building failure, (2) evaluate the technical aspects of evacuation and emergency response failures, (3) recommend as necessary specific improvements to building standards, codes and practices, and (4) recommend any research and other appropriate actions needed to improve the structural safety of buildings and improve evacuation and emergency response procedures, based on the findings of the investigations. The Act requires that NIST issue a public report no later than 90 days after completing an investigation.

Within 48 hours, NIST will examine the relevant factors associated with building failures that occur as a result of the earthquake and will make reasonable efforts to consult with the other NEHRP agencies prior to determining whether to conduct an investigation under the Act. Any NIST investigation conducted under the authority of the Act will be limited to building failures on one or more buildings or on one or more class or type of buildings selected by NIST.

\subsubsection{Phase II}

\subsubsection{Phase II Meeting (NEHRP Investigations Coordinator)}

When initial reconnaissance activities have been completed and initial assessments of earthquake effects and damage have been made, typically within a few days to a week, it will be the responsibility of the Investigations Coordinator to convene a meeting to identify opportunities and needs for further investigation and concentrated data gathering. This meeting should involve leaders of the field efforts and include representatives from the USGS, FEMA, NIST, NSF, EERI, earthquake engineering research and education centers, earth science centers, IRIS, UNAVCO, state agencies, multi-state consortia, and groups representing the earth science, engineering, and social sciences communities. The meeting is referred to in figure 1 as the Phase II meeting. The primary purpose of the meeting is to identify important or unique geologic and seismologic effects, damage to the built environment, and societal impacts for which concentrated short-term investigations and data gathering are required to ensure that important information is collected before it is lost or obliterated. It is particularly important to identify opportunities to collect important perishable data, such as data on structural and lifeline performance, aftershocks, and ground failure, including fault rupture and secondary deformation. These are investigations 
that must be conducted quickly before effects and damage are obliterated by recovery efforts and natural processes. In retrospect, important data have been lost following past earthquakes that could have been used to develop better engineering criteria and other hazard mitigation tools. As a consequence, valuable lessons were not learned and many needed tools to reduce losses and casualties have not been developed.

Within 24 hours after the meeting, the Investigations Coordinator shall prepare a brief summary of the meeting for the NEHRP agencies that describes (1) major preliminary findings of the reconnaissance teams and (2) opportunities for further investigations identified by participants in the meeting. The summary shall consider hazard mitigation and risk management priorities in applicable local and state hazard mitigations plans while identifying investigation priorities. The report shall include an estimate of the level of additional support required to pursue these opportunities. On the basis of this report of the Investigations Coordinator, NSF, the USGS, EERI, the earthquake engineering research and education centers, and earth science centers shall work jointly to optimize the collection of perishable data.

If recommendation 4 (see 5.4) to seek additional funds to increase the level of post-earthquake support is successful (or if supplemental funds are appropriated), it is recommended that a statement, which is jointly prepared by FEMA, USGS, NSF, and NIST, of opportunity for directed data collection be posted on the USGS and EERI event Web sites and the NSF Web site soliciting statements of qualifications and funding requests from groups or organizations willing to conduct data gathering. This statement of opportunity should specifically identify urgent investigations and note that funding decisions will be made quickly by the process described in recommendation 4. Data gathering teams responding to this statement of opportunity will typically include professors and students, representatives from both the earthquake engineering research and education and earth science centers, representatives of state and Federal agencies, personnel from professional organizations, and groups from engineering and other private firms.

If recommendation 4 is not successful (or if supplemental funds are not appropriated), the report should be used to take maximum advantage of available NEHRP and other resources. These resources include those of (1) NSF, which may supplement existing research contracts and award both new peer-reviewed grants and Small Grants for Exploratory Research (SGER), (2) USGS, which redirects agency personnel and their research funding, (3) FEMA, whose engineering studies support recovery as specified under the Stafford Act, (4) NIST, which has the authority to conduct building investigations, and (5) the earthquake engineering and earth science centers, which provide support from discretionary funds. If NIST is conducting an investigation under the authority of the National Construction Safety Team Act, NIST will use its available resources for the conduct of its investigation. In addition, the NSF award to EERI to support the Learning from Earthquakes Program now includes funding for a few small grants for post-earthquake data collection. Because these resources are collectively modest and typically do not pro- vide for comprehensive documentation of earthquake damage and effects, it is imperative that they be directed towards investigations of highest priority. This will require that these institutions work together before making awards.

To improve the utility of data gathered during Phase II, NEHRP needs to standardize formats for data gathering and archiving. This is the purpose of recommendations 1,2 , and 3 (see 5.1, 5.2, and 5.3). We strongly encourage the NEHRP agencies to begin developing these standards and a process for electronically archiving these data before NEHRP is confronted by the next significant earthquake. While the success of recommendation 4 would provide funding that could support implementation of this activity, planning must be completed before the next earthquake.

\subsubsection{Budget Supplemental Decision (FEMA, NIST, NSF, USGS)}

If the earthquake presents opportunities for investigations that would improve earthquake risk mitigation, but which cannot be supported with existing funds, the NEHRP agencies shall convene and consider a request for a budget supplement within a few days after the earthquake. The meeting shall be convened when field reports are adequate to make strategic decisions about these opportunities. This meeting will be unnecessary if the potential permanent funding sources have been established (see 5.4).

\subsubsection{Phase III}

\subsubsection{Workshop for Setting Investigation Priorities (NSF, USGS, FEMA, NIST)}

Establishing priorities for long-term investigations, development, and implementation strategies following significant earthquakes is an important challenge for NEHRP. Large damaging earthquakes typically provide many opportunities to improve the understanding of earthquakes and their impacts. The NEHRP agencies (NSF, USGS, NIST, and FEMA) and appropriate state agencies and multi-state consortia shall jointly sponsor a workshop of earth scientists, engineers, and social scientists within 1 to 2 months of significant earthquakes to discuss priorities for long-term (Phase III) research and development opportunities presented by the earthquake. The workshop shall consider priority initiatives in applicable local and state hazard mitigation plans when evaluating investigation priorities. The format adopted in the EERI workshops following recent foreign earthquakes is a possible model that might be supported by NEHRP. These EERI 2-day workshops have served effectively to identify the most promising research opportunities - those that have the greatest potential to improve the current state of knowledge and practice throughout the world's seismic zones. The results of the NEHRP workshop will be presented immediately afterwards in a report that identifies major needs and opportunities for investigation, with a recommended set of priorities for funding.

Within the constraints of available funding, a joint statement shall be issued soliciting long-term research and inves- 
tigations. Funding shall be made within approximately 5 months of the event. The internal post-earthquake research activities of the USGS, FEMA, and NIST shall be coordinated with externally supported research of the NEHRP funding agencies.

\subsubsection{Information Dissemination (USGS, NIST, NSF, FEMA)}

The publication and dissemination of findings from NEHRP post-earthquake investigations currently are both inconsistent and incomplete. Research findings are published in a wide variety of journals in a more or less timely manner, but official publications of the participating organizations often are not available until years after the event. This significantly reduces their potential impact on both earthquake-related knowledge and loss-reduction policy. This plan envisions that three different types of publications will be issued either under the aegis of or with facilitation by NEHRP for every significant domestic earthquake (these are not meant to preclude publication of institutional reports like those currently prepared after significant earthquakes):

- Three-Month Event Summary_An event summary for a broad audience shall be published within 3 months of a significant earthquake. The summary should be well illustrated, comprehensive, and integrate preliminary observations on the seismological processes controlling the event and the response of the natural, built, and socioeconomic environments. It is recommended that the event summary be prepared under the leadership of the USGS and EERI with formal collaboration of FEMA, NIST, and other NSFfunded entities. For example, the contributions of all of the major engineering and earth science investigative efforts supported under NEHRP should be integrated and incorporated. The USGS and EERI should designate editors within 1 week of the event, but co-editors from contributing agencies and centers should be included to facilitate agency participation. The summary is intended as a multidisciplinary document covering the earth sciences, engineering, and social sciences. It is not intended to substitute for institutional reports such as the EERI reconnaissance report, the USGS circular, and center reports that currently are produced following significant earthquakes.

- One-Year Conference Proceedings-Because of the opportunity to implement change in the aftermath of disasters, FEMA, NIST, NSF, and the USGS will encourage and support local and state agencies in sponsoring a public conference with a proceedings on the 1-year anniversary of a significant earthquake. The conference should identify and synthesize the policy implications of the event for earthquake risk reduction. NEHRP agencies shall participate and provide support to the state agencies as needed to promote a successful conference. The conference and proceedings would be analogous (but without the legal implications) to transportation disaster assessments by agencies, like the National Transportation Safety Board, that investigate transportation accidents to determine causality. Another model is the 1995 Earthquake Information Exchange Workshop, which was held following the 1994 Northridge, California, earthquake. The anniversary conference should be held in the region impacted by the earthquake and the content of the conference should be designed to target an audience of local and state policymakers in addition to Federal stakeholders. It is also expected that NEHRP will sponsor technical conferences, as is the current practice.

- Comprehensive Synthesis (3 to 5 Years)_A comprehensive report that consists of one or more volumes that synthesize the results and findings from studies carried out by the research and professional practice communities shall be published within 3 to 5 years of the event by the USGS and NIST, with assistance from NSF and FEMA. The cost of this publication shall be shared among the NEHRP agencies. The report shall emphasize the significant contributions of the post-earthquake investigations to the knowledge base on earthquakes and earthquake loss reduction and bring relevant data together in a summary fashion. The report shall be coordinated with the data archive discussed later (see 5.3) where detailed investigations of representative structures, including plans, design criteria, estimated force distributions, and displaced shapes could be presented. The report should contain overviews of important findings derived from research on earth sciences and on the built and socioeconomic environments. This synthesis should include an extensive bibliography of the post-earthquake publications and should focus both on damage and disruption and on situations where the built environment performed well and little or no damage occurred. A comprehensive Phase III synthesis is important for several purposes to researchers and practitioners, including providing both rapid entry into the literature on the earthquake and overviews of studies that have been conducted in different disciplinary areas. A synthesis also distills significant lessons learned for future research, practice, and loss-reduction policy. Finally, NEHRP shall publicize the report to both the research and practice communities.

If NIST is conducting an investigation under the authority of the National Construction Safety Team Act, NIST will contribute to the publications described above to the extent possible.

\subsection{Foreign Earthquakes}

NEHRP supports investigations of foreign earthquakes because they often provide special opportunities to validate models and to learn about both the performance of specific aspects of the built environment and the geologic and seismologic processes that will have implications for earthquake risk mitigation in the United States. Cost and logistics generally limit the size of NEHRP foreign postearthquake investigations. Federal agencies generally do not participate unless officially invited by the impacted country. These factors cause tremendous differences in the character of individual investigations. At one extreme, investigations are modest and limited to small EERI reconnaissance teams, as for example, with the 1992 Erzincan, 


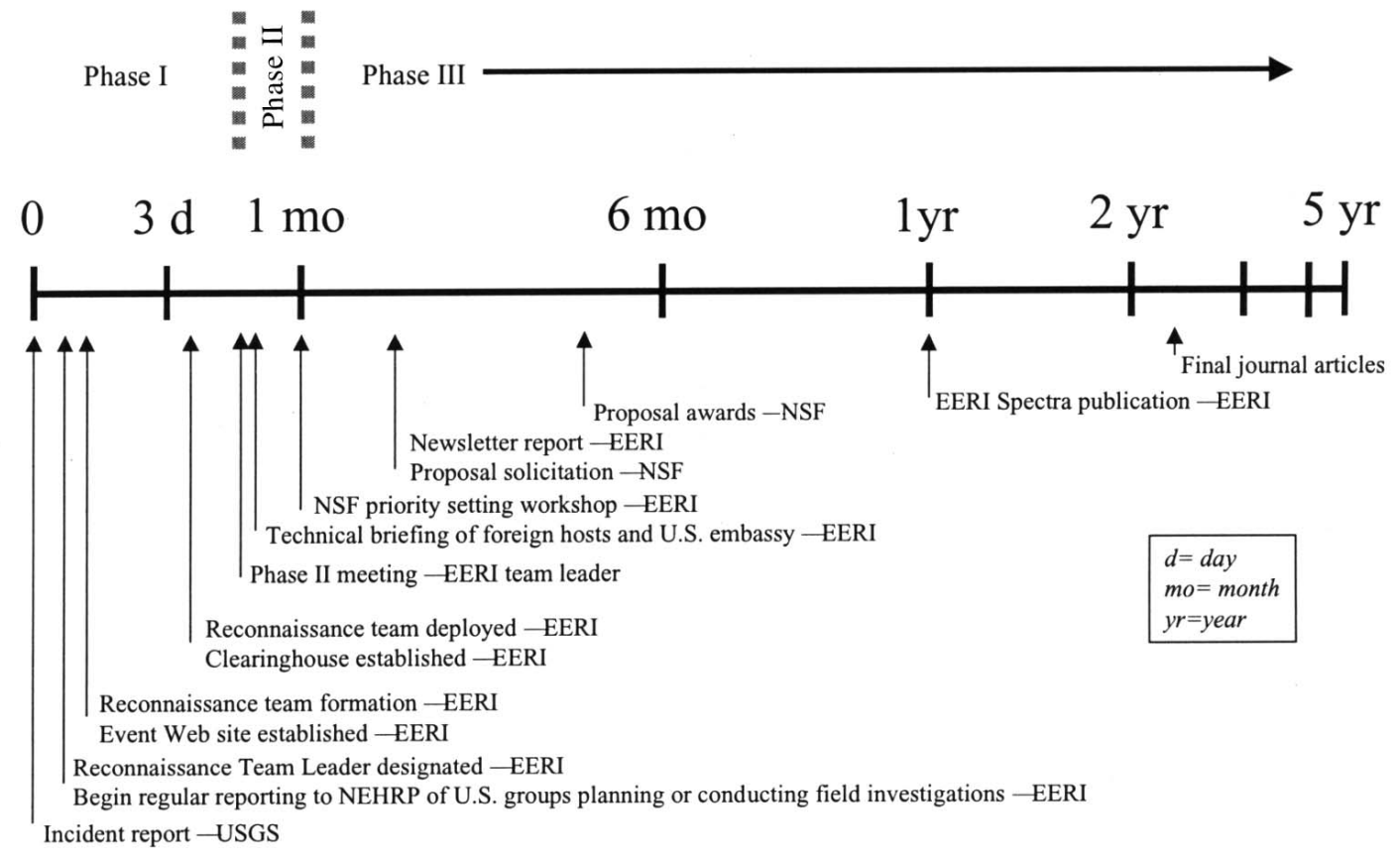

Figure 3. Activities timeline for EERI post-earthquake activities-Foreign earthquakes.

Turkey, earthquake. At the other end of the spectrum, affected foreign governments request U.S. assistance and these investigations have foreign policy implications, as with the 1988 Armenia, USSR, 1995 Kobe, Japan², and 1999 Kocaeli, Turkey, earthquakes. In the latter situation, some of the investigating teams are representatives of the U.S. Government while others, who are not covered by the request, are independent.

Failure to coordinate schedules of field teams may lead to interference with the work of local experts and is the principal operational issue for NEHRP-supported foreign deployments. U.S. institutions typically respond independently in the earth sciences, engineering, and social sciences. Field parties supported by the EERI Learning from Earthquakes Program, the three earthquake engineering research and education centers (MAE, MCEER, and PEER), SCEC, CERI, IRIS, UNAVCO, as well as individuals with small NSF grants for exploratory research (SGER) may all visit earthquake-damaged areas with Federal funding support. In addition, the USGS, NIST, private firms from both the U.S. and foreign countries, and research entities from foreign countries commonly deploy field teams. The uncoordinated deployment of U.S. citizens has prompted complaints by affected countries to the U.S. Department of State.

In its recent award to EERI for the Learning from Earthquakes Program, the Civil and Mechanical Systems directorate of NSF requested that EERI coordinate investigators funded by that directorate. In investigations in Turkey in 1999 and India in 2001, EERI has increasingly served as a point of contact for foreign post-earthquake

\footnotetext{
${ }^{2}$ In this case, the Japanese request for U.S. Government assistance was delayed for more than a month following the event.
}

investigations. This plan recommends that NEHRP expand this EERI role. This plan recommends that each NEHRP agency request all of its post-earthquake investigators to inform EERI of plans and schedules of their investigations before departure as well as their ongoing status once they are in the field. EERI shall report these planned activities and their status regularly to the NEHRP agencies and post this information on its Web site. Because authority to influence schedules rests with the NEHRP funding agencies, the agencies shall review proposed plans for their potential impact on the proposed country.

Although it is beyond the scope of the NSF mandate to EERI, this plan encourages EERI to keep local technical and scientific personnel abreast of U.S. activities, to involve them in these activities where possible, and encourage them to communicate relevant findings directly to the government of the country affected by the disaster. These communications from local personnel may be useful for reconstruction as well as encourage mitigation of future losses.

It is noted that EERI in its Learning From Earthquakes Proposal to NSF has strengthened the coordination role of the EERI Team Leader and group leaders for each of the disciplines. In the field they solicit cooperation with other investigators. In preparing the preliminary and final EERI reports, they solicit and coordinate contributions from others who participated in field investigations. The EERI Team Leader also plays a significant role in helping to coordinate the second phase of data collection by making contact with each of the investigative teams before they enter the field and maintaining contact with them during field investigations by e-mail and phone. The EERI Team Leader offers to direct these investigators to areas that require further investigation before perishable data are lost. The approach allows researchers to collect data in several 
waves, improving the comprehensiveness of the documentation of earthquake impacts. Coordinating field investigations and drawing on contributions from other teams ensures a clear understanding of damage and impacts, less duplication, less disruption of local emergency response and research efforts, more effective utilization of limited research funding, and a more comprehensive report on the earthquake. The EERI post-earthquake investigation plan is shown in figure 3 .

\section{Recommendations for Further Action}

At the March 13-14, 2001, invitational workshop held to provide input for this draft plan, participants identified several aspects of NEHRP post-earthquake investigations that are deficient. These deficiencies diminish the potential contribution of NEHRP to risk reduction in the United States. Aspects in need of improvement include the following:

- Comprehensiveness - Investigations of earthquake impacts do not comprehensively cover all aspects of the natural, built, and socioeconomic environments.

- Efficiency-Emerging new information and technologies can greatly increase the quality and quantity of data collection, while lowering costs.

- Data storage and retrieval-Much of the data that has been collected in past earthquakes has been effectively lost. If data collection is to become even more comprehensive, data management, archiving, and linking to existing data must be improved.

The following recommendations propose solutions to these interrelated deficiencies. The objectives of the first 3 recommendations are to improve the scope (Recommendation 1), the quality and quantity (Recommendation 2), and the utility (Recommendation 3) of data acquired during post-earthquake investigations. Recommendation 4 proposes mechanisms for funding these improvements.

\subsection{Recommendation 1-Broaden Coverage and Comprehensiveness of Investigations of Earthquake Impacts}

\section{Issue_-Impacts on built and socioeconomic environments are not well documented}

Research on the impacts of earthquakes on the natural environment (for example, seismology, ground motion, and permanent ground deformation) is relatively well organized and documented by NEHRP because the USGS has both budgetary and operational responsibility in this area. The result has been significant improvement by both USGS and non-USGS scientists in the basic understanding of the natural consequences of earthquakes, such as shaking and permanent ground deformation.

In contrast, performance data on the built environment (for example, buildings and lifelines) are not systematically compiled. Documentation of the seismic performance of nonstructural components in facilities is particularly lacking. This failure to document fully the physical impacts of an earthquake has serious consequences because full-scale testing of the performance of engineered systems under dynamic loading is often impractical. Because damaging earthquakes are infrequent, each failure to systematically document damage is a lost opportunity to improve:

- Performance-based design.

- Loss estimation.

- Safety assessments of badly damaged structures.

The current trend in earthquake engineering is to base seismic risk evaluations and design decisions on the predicted behavior of structures and their components during assumed levels of earthquake ground shaking. This approach, called performance based earthquake engineering, shows great promise as a framework to enhance the ability of both the private and public sectors to identify and to quantify levels of risk, to develop cost-effective strategies for risk reduction activities, and to implement efficient seismic rehabilitation. Yet these techniques rely completely on assumptions on the part of engineers of the actual performance of the built environment. An overly optimistic view can overlook significant risks or lead to ineffective designs. In the other extreme, excessive conservatism leads to unnecessarily high costs or, worse yet, inaction in the face of a seemingly insurmountable problem. Effective decisions on the part of building owners and managers, insurance and financial institutions, and public policymakers require realistic predictions of expected behavior in a statistical context. Extensive documentation of actual behavior, good and bad, of a broad range of structures subjected to real earthquakes will provide the data to meet this critical need.

These data that document performance of the built environment are also essential for improving earthquake loss estimation models. Predictions of earthquake impacts with computer-based loss estimation models are becoming increasingly common in both the private and public sectors because the rarity of large damaging earthquakes does not permit robust actuarial estimates of future losses. Comprehensive documentation of the impacts of future earthquakes will improve model-based estimates of structural and nonstructural damage, casualties, and financial loss.

Documentation of the performance of the socioeconomic environment also is very incomplete. Increasingly post-earthquake investigations include social, organizational, and economic issues, but much more progress is needed. For example, despite their obvious importance, relatively little emphasis is currently being placed on the systematic collection of data on earthquake-related deaths and injuries, both for U.S. and foreign earthquakes. The same can be said for other topics of major societal relevance such as the short- and longterm social and economic impacts of earthquakes, including impacts on regional economies, communities, households, and businesses. Because of its importance, the organization 
and effectiveness of emergency response and relief activities should be routinely documented.

\section{Potential Solutions}

\section{Built Environment}

Two aspects of structural performance surveys are particularly important-(1) adequate inventories of the building stock and others structures at risk and (2) systematic documentation and compilation of both damaged and undamaged structures. The lack of adequate data inventories hampers assessment of the significance of observed damage in many cases. Inventories make it possible to characterize the damage data and place it in proper context. For example, the knowledge that 1,000 steel buildings in the 1995 earthquake in Kobe, Japan, suffered significant damage is incomplete information and fails to answer questions such as "How many steel buildings were subject to strong ground shaking?" or "Where were the damaged buildings located relative to the fault?"

Fortunately, with the increasing application of standardized procedures for (1) seismic design of structures, (2) preevent evaluation and rehabilitation of structures [see FEMA 310 (ASCE,1998a) and 356 (ASCE, 1998b)], (3) post-event evaluation and repair of structures [FEMA 306/307/308 (ATC, 1998a,b,c)], and (4) damage prediction [FEMA 154 (ATC, 1988), HAZUS@ (HAZUS, 1999)], a framework is emerging in the United States for both the collection of performance data and the development of inventories. For example, HAZUS@, which was developed by FEMA to standardize loss estimates from earthquakes and other natural hazards, provides a framework for inventories of facilities and the description of performance. This plan recommends that NEHRP adopt a format for documenting performance that is consistent with these methodologies. It also recommends that NEHRP through FEMA also promote the development of robust inventories of structures by working with HAZUS@ users groups and others who have adopted and adapted these procedures. Important work in these areas is already ongoing at the NSF-funded earthquake engineering and research and education centers.

This plan recommends that the systematic documentation and compilation of damaged and nondamaged structural performance, as well as the documentation of earthquake resisting properties of structures, be spearheaded by FEMA and NIST, because the data also would ultimately be used to improve building codes and standards and practices for structures and lifelines. The format for this documentation shall be established by FEMA and NIST before the next earthquake and could be similar to the ATC-38 post-earthquake building performance assessment form (ATC, 2000) and the EERI clearinghouse report form (S. McAfee, written commun., 2001; EERI, 1996). The actual surveys could be conducted by a contract with engineering organizations, such as American Society of Civil Engineers (ASCE), National Council of Structural Engineers Association (NCSEA), and ATC under the supervision of FEMA and NIST. In the absence of the success of Recommendation 4 for supplemental funding, it is unclear how the postearthquake damage surveys will be funded.
The extensive and detailed information on the damage to facilities that is routinely compiled by FEMA as a part of the disaster assistance funding process and by private structural engineering and design firms are existing valuable sources of information that are not currently available for research purposes. Coordination with FEMA and private firms to capture these data would provide a large source of additional data $^{3}$. Once the collection of data on the built environment is improved, the data must be appropriately archived and made available. This can be accomplished by promotion of a NEHRP database (see Recommendation 3).

\section{Socioeconomic Environment}

A wider range of disciplines and specialists also needs to be incorporated into post-earthquake reconnaissance activities. Although there has been movement in the direction of greater disciplinary diversity, post-earthquake reconnaissance activities are undertaken primarily by earth scientists and engineers. Groups that remain underrepresented in post-earthquake investigations include public health specialists (such as epidemiologists), researchers from the various social science disciplines (for example, economics, sociology, geography, and political science), and experts from the emergency management and public policy communities.

Mechanisms must be established to encourage greater participation by investigators with expertise in the social science and public health fields, experts in economic modeling, and others who can contribute to the collection and analysis of data on the pre- and post-impact social environment. NEHRP should coordinate and work with organizations involved in studying the socioeconomic and public health aspects of disasters to recruit and train a cadre of qualified health and social science investigators who can participate in future post-earthquake studies. A partial list of these organizations include the U.S. Centers for Disease Control and Prevention, the University of California at Los Angeles Center for Public Health and Disasters, leading social science centers such as the Natural Hazards Research and Applications Information Center at the University of Colorado and hazardfocused geographic information system (GIS) laboratories such as the Hazards Research Lab at the University of South Carolina, and professional associations such as the International Research Committee on Disasters. As an initial step, EERI should initiate outreach efforts aimed at informing social science and public health researchers about NEHRPrelated post-earthquake data collection opportunities and more effectively integrate members of these groups into postearthquake investigations.

EERI should also seek input from social scientists on how to improve the quantity and quality of data that are collected on the societal aspects of earthquakes. As is the case with other disciplines involved in post-earthquake investigations, new protocols are needed to ensure that the data-collection strategies and instruments that are used to

\footnotetext{
${ }^{3}$ Previous studies have emphasized the need for systematic collection and compilation of economic impacts (see NRC, 1999).
} 
obtain data on the social, economic, and health impacts of earthquakes are standardized, so that comparisons can be made across time and across earthquake events. Existing documents such as the EERI Post-earthquake Investigation Field Guide outline in broad terms the types of social and economic impact data that should be obtained during the post-earthquake reconnaissance phase. This guide should be reviewed, revised, and expanded to incorporate a broader range of social science data as well as to provide more systematic frameworks for recording those data. When revised, the guide should be distributed widely within the social science research community.

Agencies that sponsor post-earthquake investigations should also recognize that gaps in knowledge exist because many disciplines and topics lack adequate funding. In making funding decisions, NEHRP agencies should examine how to ensure better disciplinary coverage so that significant research topics-including those focusing on the socioeconomic environment-are not overlooked. Both the Investigations Coordinator and the entities responsible for organizing the Phase II and III meetings to set priorities shall be responsible for ensuring that significant socioeconomic issues are included in the research plans that are developed and that adequate funding is available to support that work. Finally, societal impact data must be placed in a larger context. For example, this could be done through the systematic collection of data on both pre- and post-event characteristics of affected communities, populations, and economies.

\subsection{Recommendation 2-Encourage Use of Information Technology}

\section{Issue - Information Technology (IT) offers opportunities to improve collection of data}

Data that are amenable to collection using remote sensing, digital imaging, global positioning system, and other new and emerging technologies are distributed widely within the natural, built, and social environments. A wide variety of data, which previously could not be collected or only collected at great effort, can now be collected and analyzed rapidly, often in near-real time. Examples include the following:

- Regional geodetic and geological effects.

- Recordings of strong shaking on the ground and in engineered structures during the main shock.

- Aftershocks.

- Ground deformations associated with faulting, liquefaction, landslides, and shaking.

- Direct and indirect damage to structures and lifelines (both in a regional statistical sense and in detailed studies of selected structures).

- System responses, such as pressures and flows in gas, water, and wastewater systems, telephone demand surges, and traffic patterns.

- Collateral dynamic phenomena, such as growth and spread of post-earthquake fires and spills of hazardous materials.

- Data on earthquake casualties and on other social and economic impacts.

\section{Potential Solution}

Advances in information technologies now permit rapid, cost-effective collection and analysis of virtually exhaustive data sets in each of the above categories. A few examples of current, but only recently available technologies include the following:

- PDA-GPS-digital camera technology to permit standardized but rapid and extensive digital descriptions of georeferenced damage data for regional and detailed structure and lifeline damage studies.

- Remote sensing (for example, InSAR, LIDAR) for compilation of inventories of the visible built environment before and immediately after the main event, for regional assessments of damage.

- Digital recording and near-real-time dissemination of strong shaking measurements throughout the affected built environment during the occurrence of damage from the main earthquake to provide the quantitative recordings needed for emergency response, performance-based engineering, and the rebuilding of a safer society.

- High-resolution low-altitude vertical and oblique aerial photographs as a mandatory part of the NEHRP post-earthquake reconnaissance, to be made available free on the Internet.

- On-site digital video image capture by special imagecapture vans with mounted digital cameras to document building status on both sides of a street immediately following the event.

- Supervisory Control and Data Acquisition (SCADA) data for understanding of the real-time impacts and response to earthquakes of distributed systems such as gas, water, and wastewater systems. SCADA systems have emerged as a typical feature of lifeline networks over the last several decades - the data are generally available but have been little used for studying the effects of earthquakes, damage and post-earthquake response, and demands on distributed systems.

It should also be mentioned that while not observational data, both ShakeMap and HAZUS@ results can be valuable adjuncts to post-earthquake investigations (in addition to emergency response). Existing GIS inventories of the built environment can guide comprehensive inspection and data collection for essential facilities and infrastructure.

These are only a few examples of relatively new technologies that can be used more effectively in post-earthquake investigations. IT is developing so rapidly that new tools and applications are emerging constantly. In order to enhance post-earthquake investigations and analyses, this plan recommends that NSF, USGS, NIST, and FEMA support ongoing research into applications of IT and ways to analyze and use 
the collected data. The NSF-funded earth science organizations and earthquake engineering research and education centers provide excellent resources for this effort. We also recommend that, in the immediate response to the event, NSF, USGS, NIST, and FEMA support equipment and other resource needs and facilitate access to and use of selected IT assets that may be beyond the resources of individual investigators (for example, if FEMA tasks national reconnaissance assets to fly over a domestic earthquake the imagery should be available to NEHRP-supported investigations to the maximum extent feasible). If NIST is conducting an investigation under the authority of the National Construction Safety Team Act, NIST will support this solution to the extent possible.

\subsection{Recommendation 3-Formalize Data Management and Archiving}

\section{Issue-Collected data are not well archived and therefore are effectively lost}

It is critical to develop strategies for the formal and systematic archiving of data collected during post-earthquake investigations. These data, which focus on the natural, built, and socioeconomic environments, address a wide variety of phenomena. The data are voluminous and are acquired in many forms (for example, digital recordings, digital images, clipboard survey sheets, photographs, and narratives). If not organized and archived soon after an earthquake event, these data are often lost. No mechanism currently exists either to archive these data or to make them readily accessible to the research community. Because of this failure to adequately document, preserve, and access data, an enormous volume of highly relevant data has been effectively lost.

\section{Potential Solution}

Management of these data requires:

- Research on cost-effective field data collection-Much of the initial data from post-earthquake investigations are collected on foot in the field. Use of georeferenced personal digital assistants and digital and video cameras with GPS capability and other efficient data collection tools should be encouraged by the development and free dissemination of standardized software applications and associated data protocols for use both in the field and for downloading data.

- Development of a consensus-based repository for collected data - Rather than relying on physical repositories, technology now permits most data to be digitally recorded and stored. Therefore, this plan recommends the creation of a virtual web-based archive, analogous to the structure and functioning of the Consortium of StrongMotion Observation Systems (COSMOS) Virtual Data Center (http://db.cosmos-eq.org/). This new database, to be called the "National Earthquake Experience Database" (NEED) should be maintained at individual centers, but retrievable from a single or mirrored Internet site using time stamps and a geocoded referencing system. NEED would be addressable with all of the tools of a modern GIS, as well as with modern relational database technology on the Internet. Researchers could contribute to it from any location, according to established quality control guidelines. NEED will fill the need for a permanent, interactively managed national and international archive for the unprecedented data sets to be collected from future damaging earthquakes.

One approach to this effort would be to require each recipient of NEHRP funding (NSF grantee, the earthquake centers, USGS awardees, NIST, and others) to budget a percentage of the grant funds (for example, 1 or 2 per cent) for archiving raw and reduced data in NEED. Alternatives for management and maintenance of NEED include:

(1) Integration into and management by the Network for Earthquake Engineering Simulation (NEES).

(2) Residency in the National Information Service for Earthquake Engineering (NISEE), and with oversight by a board consisting of representatives of organizations such as MCEER, PEER, MAE, EERI, Seismological Society of America (SSA), ATC, and Consortium of Universities for Research in Earthquake Engineering (CUREE). NEED could reside on the NISEE server with mirror servers on the MAE, MCEER, and PEER servers.

(3) Residency in the NSF Digital Library for Earth Science Education (DLESE).

The costs associated with implementing this solution range from research funding focused specifically on the integration of new technologies into post-earthquake investigations to providing funds for a workshop where investigators share information on their data collection and archiving strategies and to supporting a Web site where data-sharing will be accomplished. Each level of effort has an associated cost. Once the data repository format has been established, implementation of a consensus-based repository can be accomplished. Dedicated costs for creation and maintenance of NEED would be perhaps two staff-years to start, and one staff-year annually thereafter, with hardware and expenses perhaps in the tens of thousands of dollars annually. Contribution of data into NEED would be a distributed cost, borne by each contributing investigation. This plan recommends that all NEHRP-supported investigations be required to budget a small fraction of the investigation's overall costs for this purpose.

\subsection{Recommendation 4-Funding to Support Post-Earthquake Investigations}

\section{Issue_-Funding of post-earthquake investigations is inadequate}

The absence of readily available financial resources to fund immediate, short-term, and long-term post-earthquake investigations has resulted in the failure to collect valuable 
data vital for development of earthquake disaster reduction measures and has handicapped substantial follow-up research investigations. For the 1989 Loma Prieta, California, earthquake, Congress enacted "Emergency Supplemental Funds" for use by the NEHRP agencies for post-earthquake investigations. The emergency supplemental funding provided by Congress following the 1989 Loma Prieta earthquake was $\$ 20$ million, of which $\$ 8$ million was designated for post-earthquake investigations administered by USGS. The emergency supplemental funding provided by Congress following the 1994 Northridge earthquake was \$13 million. It was recognized that this is neither the best nor the most efficient means to fund these efforts ${ }^{4}$. The report to Congress by FEMA (1993), which was requested in the 1990 reauthorization bill, provides an excellent summary of the benefits of post-earthquake investigations and suggests several alternative approaches to establishing a fund for this purpose. It was clear that the four principal NEHRP agencies could not agree on a single best approach.

\section{Potential Solution}

One possible solution for funding domestic post-earthquake investigations to be used when an earthquake has been designated as a Presidentially declared disaster could be obtained by establishing a separate fund during the next NEHRP reauthorization that could then be drawn upon for Federally-declared earthquake disasters; such funds could be administered by FEMA. Another possibility could be to designate and utilize existing agency programs to fund these activities. However, in the absence of such funds, all of the NEHRP agencies shall be prepared to submit a request through FEMA to Congress for appropriate emergency supplemental funding following a significant domestic earthquake. Such a template could be used as well for post-event investigations of other types of disasters, including natural and terrorist events, which would allow for the documentation of information that would help improve the protection of the Nation's infrastructure from future events.

Foreign post-earthquake investigations could continue to be funded on a basis of need from each of the NEHRP agencies.

Background - The issue of funding of post-earthquake investigations is a very significant one and received considerable attention at the March 2001 workshop and subsequently by the authors. One alternative that was explored but ultimately not included in the recommendations was the possibility of utilizing the Stafford Act to provide funds for post-disaster investigations. The amount of funds could be equal to 1 percent times the Section 406 disaster relief funds ${ }^{5}$. For the Loma Prieta earthquake this would have amounted to about $\$ 28$ million, and for the Northridge earthquake it would have totaled about $\$ 60$ million. The funds made available by such change in the Stafford Act

4Public Law 101-614, National Earthquake Hazards Reduction Program (NEHRP) Reauthorization Act, Section 11 (b), November 1990.

${ }^{5}$ For comparison, Section 404 currently provides between 15 and 20 percent times the 406 expenditures for hazard mitigation grants. For the Northridge earthquake this amounted to about $\$ 722$ million. could also be used to provide post-disaster funds for disaster related investigations following other natural events such as hurricanes and, even more significantly, man-made events such as acts of terrorism. However, this alternative was not included in the report's recommendations because any proposed new language modifying the Stafford Act would require action by Congress, which is unlikely at the present time.

Because the funding of post-earthquake investigations remains a crucial issue, this plan recommends that all NEHRP agencies be prepared to submit a request through FEMA to Congress for appropriate emergency supplemental funding following a significant domestic earthquake.

Recommended Administration-With any of the funding mechanisms discussed above, this plan recommends that FEMA, as lead NEHRP agency, be responsible for the identification of investigation topics, distribution of the funds, and reporting of the results to Congress ${ }^{6}$. For earthquake disasters, it is recommended that the NEHRP Policy Coordinating Group, Presidentially appointed individuals from the four principal NEHRP agencies, create a standing nine-member post-earthquake investigation Selection Committee to assist FEMA in fulfilling these responsibilities. This Selection Committee shall be mobilized within days after a significant earthquake, attend all briefings, participate in the joint NSF/USGS/FEMA/NIST priority-setting workshop, and be responsible for identifying the basic and problem-focused investigation efforts required to maximize learning from the specific earthquake disaster. On the basis of the outcomes and recommendations of the workshop, the Selection Committee shall recommend to FEMA topical areas and funding levels for each area. FEMA would determine the funds to be allocated to each NEHRP agency. Each NEHRP agency shall be responsible for the identification of appropriate projects and investigators, administration of its grants, project supervision, and be accountable for funds allocated to their agency in their topical areas. They will actively contribute to the report to Congress. The nine members of the Selection Committee shall consist of one member from each of the four principal NEHRP agencies and at least four members from the non-Federal earthquake community.

\section{Annual Review of Plan}

The United States historically has been fortunate that large damaging urban earthquakes have been infrequent. This is due more to the relatively recent formation of the United States as a nation than to a lack of seismicity. Potentially damaging earthquakes, such as the 1811-12 New Madrid sequence in the Midwest, the 1755 Cape Anne, Massachusetts, and 1886 Charleston, South Carolina, events on the east coast, the 1857 Fort Tejon event in southern Califor-

\footnotetext{
${ }^{6}$ FEMA currently reports to Congress on hazard-mitigation grant projects funded by Stafford Act Section 404 even though these projects are selected by the state for which the disaster has been declared and approved by FEMA before expenditure.
} 
nia, and the 1700 mega-event in the Pacific Northwest, are all well documented, but occurred before major urban or suburban development of the regions. In modern times, the only large $(M>7)$ earthquakes that affected U.S. cities were the 1906 San Francisco, California, and 1964 Good Friday, Alaska, earthquakes, both of which devastated cities. Smaller $(\mathrm{M}<7)$ but more frequent modern events, however, such as the 1971 San Fernando, 1989 Loma Prieta, 1994 Northridge, and 2001 Nisqually earthquakes, offer opportunities to learn how to reduce earthquake risk - the ultimate goal of NEHRP.

Thus, opportunities to implement this proposed plan in its entirety will only happen irregularly. As normal turnover in NEHRP management occurs, however, new managers may be unfamiliar with the plan. Implementation of the plan is further complicated by NEHRP's lack of a line-management structure to activate this plan immediately after an event. Therefore, it is recommended that the NEHRP Interagency Coordinating Committee (ICC) review this plan annually, and after each review remind agency and institutional managers of their obligations under the plan. The annual review should also include an opportunity for comments from the professional and research community involved in earthquake risk mitigation. It is recommended that this annual review occur on the anniversary of the largest recorded earthquake in U.S. history, the March 27, 1964, Good Friday earthquake in Alaska.

The annual review would provide opportunities to revise or modify the plan as appropriate. A fundamental tenet of emergency management is that the process and currency of planning are as important as the plan itself.

\section{References}

ASCE, 1998a, Handbook for the Seismic Evaluation of Buildings-a Prestandard: prepared by the American Society of Civil Engineers for the Federal Emergency Management Agency, FEMA-310 Report, Washington, D.C.

ASCE, 1998b, Prestandard and Commentary for the Seismic Rehabilitation of Buildings: prepared by the American Society of Civil Engineers for the Federal Emergency Management Agency, FEMA-356 Report, Washington, D.C.
ATC, 1988, Rapid Visual Screening of Buildings for Potential Seismic Hazards: a Handbook: prepared by the Applied Technology Council, ATC-21 Report, for the Federal Emergency Management Agency, FEMA-154 Report, Washington, D.C. (FEMA-154, $2^{\text {nd }}$ Edition is in Preparation.)

ATC, 1998a, Evaluation of Earthquake Damaged Concrete and Masonry Wall Buildings, Basic Procedures Manual: prepared by the Applied Technology Council for the Federal Emergency Management Agency, FEMA-306 Report, Washington, D.C.

ATC, 1998b, Evaluation of Earthquake Damaged Concrete and Masonry Wall Buildings, Technical Resources: prepared by the Applied Technology Council for the Federal Emergency Management Agency, FEMA-307 Report, Washington, D.C.

ATC, 1998c, Repair of Earthquake Damaged Concrete and Masonry Wall Buildings: prepared by the Applied Technology Council for the Federal Emergency Management Agency, FEMA-308 Report, Washington, D.C.

ATC, 2000, Development of a Database on the Performance of Structures near Strong-motion Recordings: 1994 Northridge, California, Earthquake, Applied Technology Council, ATC-38 Report, 245 p.

EERI, 1996, Post-Earthquake Investigation Field Guide; Learning From Earthquakes: Oakland, Calif., Earthquake Engineering Research Institute, Publication 96-1, $144 \mathrm{p}$.

FEMA, 1993, Funding Post-Earthquake Investigations: Report to Congress: Federal Emergency Management Agency, Washington, D.C.

FEMA, in press, Expanding and Using Knowledge to Reduce Earthquake Losses: The National Earthquake Hazards Reduction Program Strategic Plan 2001-2005: Federal Emergency Management Agency, Washington, D.C. (Available in draft.)

HAZUS, 1999, Hazards United States: National Institute of Building Sciences, Washington, D.C.

NRC, 1999, The Impacts of Natural Disasters - A Framework for Loss Estimation: National Research Council, Washington, D.C., National Academy Press, $49 \mathrm{p}$.

OES, 1998, California Post-Earthquake Information Clearinghouse (draft): California Office of Emergency Services, Sacramento, Calif., 23 p.

OSTP, 1997, Natural Disaster Reduction Initiative: U.S. Office of Science and Technology Policy Fact Sheet, July 1997.

USGS, 1999, An Assessment of Seismic Monitoring in the United StatesRequirement for an Advanced National Seismic System: U.S. Geological Survey Circular 1188, $55 \mathrm{p}$.

Wald, D., Wald, L., Goltz, J., Worden, B., and Scrivner, C., 2000, "Shake Maps" - Instant maps of earthquake shaking: U. S. Geological Survey Fact Sheet 103-00, $2 \mathrm{p}$.

WSSPC, 2001, Policy Recommendation 01-3, Post-Earthquake Technical Clearinghouses: Western States Seismic Policy Council, Palo Alto, Calif. 
Notes 
Notes 
Notes 
Phase I Phase II Phase III

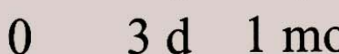

mo

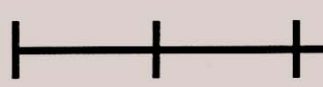

111 i.

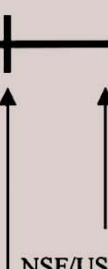

Phase II meeting - NEHRP Investigations Coordinator

Summary assessment report - NEHRP Investigations Coordinator

Budget supplemental meeting -FEMA, NIST, NSF, USGS

$d=$ day
mo= month
$y r=y e a r$

Clearinghouse established - State earth science agency/State emergency services/USGS/FEMA/EERI/Engineering and earth science centers

NEHRP Investigations Coordinator designated - USGS

NCST investigation decision-NIST

Event Web site established - USGS

Incident report - USGS

Plan Implementation Decision -USGS/FEMA/NSF/NIST/EERI/State earth science agency

Activities timeline For NEHRP Post-Earthquake Coordination Plan—Domestic Earthquakes. 